\title{
Numerical Simulation of the Head/Disk Interface for Patterned Media
}

\author{
Aravind N. Murthy $\cdot$ Maik Duwensee • \\ Frank E. Talke
}

Received: 8 November 2007/Accepted: 28 December 2009/Published online: 23 January 2010

(C) The Author(s) 2010. This article is published with open access at Springerlink.com

\begin{abstract}
The use of patterned media is a new approach proposed to extend the recording densities of hard disk drives beyond $1 \mathrm{~Tb} /$ in. $^{2}$. Bit-patterned media (BPM) overcome the thermal stability problems of conventional media by using single-domain islands for each bit of recorded information, thereby eliminating the magnetic transition noise (Albrecht et al., Magnetic Recording on Patterned Media, 2003). Considering steady state conditions, we have transferred the pattern from the disk surface onto the slider surface and have investigated the pressure generation due to the bit pattern. To reduce the numerical complexity, we have generated the bit pattern only in the areas of the slider near the trailing edge, where the spacing is small. Cylindrical protrusions were modeled using very small mesh size on the order of nanometers to obtain the flying characteristics for the entire slider air bearing surface (ABS) using the "CMRR" finite element Reynolds equation simulator (Duwensee et al., Microsyst Technol, 2006; Wahl et al., STLE Tribol Trans, 39(1), 1996). The effect of pattern height, pattern diameter, slider skew angle, and slider pitch angle on flying height of a typical slider is investigated. Numerical results show that the flying height decreases for a patterned slider and the change in flying height is a function of the pattern height and ratio of the pattern diameter to the pattern pitch. In comparison to discrete track media, the flying height loss is larger for a
\end{abstract}

A. N. Murthy $(\bowtie) \cdot$ M. Duwensee · F. E. Talke

Center for Magnetic Recording Research, University of

California, San Diego, 9500 Gilman Drive, La Jolla, CA 92093-

0401, USA

e-mail: amurthy@talkelab.ucsd.edu

M. Duwensee

Hitachi Global Storage Technologies, 3403 Yerba Buena Road, San Jose, CA 95135, USA patterned slider disk interface for the same recessed area of pattern.

Keywords Bit-patterned media Patterned slider . Magnetic data storage $\cdot$ Slider air bearing .

Finite element method

\section{Introduction}

Patterned media for hard disk drives can be used in the form of discrete tracks or discrete bits. In discrete track recording (DTR), the bits are stored on discrete circumferential tracks on the disk. In bit-patterned media, each bit is stored on a single magnetic domain or "island" [1]. Magnetic transitions no longer occur between random grains as in conventional media, since distinct boundaries between islands are formed both in the circumferential and the radial directions on the disk. Several investigations have been published that discuss the head/disk interface for patterned media. Wachenschwanz et al. [2] reported an increase in the signal to noise ratio (SNR) and a better write efficiency for discrete track type of patterned media. Head/ disk interfaces for patterned media are complicated to manufacture and pose challenging problems from a tribological viewpoint. The air bearing domain in bit-patterned media is highly influenced by the existence of surface features on the disk. Island-like cylindrical structures on the disk surface in the radial and circumferential directions change the air bearing pressure contours of the head/disk interface compared to a conventional head/disk interface with a "smooth" disk. Duwensee et al. [3] studied the influence of discrete track pattern on pressure generation in slider bearings. They reported that very high and localized air bearing pressure peaks occur in discrete track head/disk 
interfaces, and that the slider pitch angle was independent of the DTR parameters.

Gui et al. [4] and Fua et al. [5] studied padded sliders and reported that padded sliders have benefits in terms of reducing head/disk interactions and friction during contact start stop. Li et al. [6] studied the pressure of pattern on two-rail slider bearings and found that patterned sliders showed better stiction properties than unpatterned sliders. They also found that an increase in the pattern pitch and pattern height decreases the flying height. Tagawa et al. [7] investigated the effect of longitudinally grooved slider surfaces on the flying behavior of a two-rail slider flying over a smooth disk surface. Tagawa and Mori [8], [9] extended the work reported in [7] to head/disk interface for patterned media. They considered surface patterns that were on the order of 5-20 $\mu \mathrm{m}$ in width and length direction and $10-40 \mathrm{~nm}$ for the pattern height. They determined the pressure distribution for a two-rail, positive pressure slider and observed an increase in the flying height due to surface pattern. In a more recent investigation, Duwensee et al. [10] have numerically studied the head/disk interface for DTR. They investigated the effect of groove depth on the flying height and flying attitude for a constant ratio of groove width to groove pitch. They proposed an empirical expression for the flying height loss as a function of groove depth, groove pitch, and groove width. Their calculation used a very fine mesh discretization in the region of the slider air bearing surface (ABS) that is closest to the disk. A typical model consisted of $2.7 \times 10^{6}$ finite elements, $1.3 \times 10^{6}$ nodes, and required large computer memory.

Alternative techniques such as homogenization and Direct Simulation Monte Carlo (DSMC) methods have also been implemented to study the influence of surface pattern on the slider or disk surface. Buscaglia and Jai [11] applied homogenization techniques for the Reynolds equation, specifically for ultra-thin gas films with arbitrary Knudsen numbers. They considered fine but periodic surface structures on the slider disk interface. They presented the spacing between slider and disk as the sum of a low frequency contribution that is unknown and a high frequency contribution whose dependence on the low frequency is assumed to be known. The high frequency part represents the periodic spacing variations due to surface features on the disk or on the slider. The unknown part must be computed during the numerical solution of the generalized Reynolds equation. Homogenization techniques allow a coarser domain discretization than direct simulation methods. The problem size is small since only one period of the surface texture is considered due to periodicity. Also the authors show very good agreement qualitatively for the pressure fields between homogenized solution and the direct solution. The important feature of the homogenization technique is that the computation time is reduced without loss in average pressure prediction due to surface features. However, the local resolution of the pressure distribution of the air bearing is reduced due to homogenization. If details of the pressure distribution on the order of the surface features are of importance, the homogenization technique is not suitable. Alexander et al. [12] and Huang et al. [13, 14] applied the DSMC method to check the validity of the modified Reynolds equation for high Knudsen number flow in "smooth" head/disk interfaces in two and three dimensions, respectively. They reported that the DSMC method compared close to the simulation results obtained by solving the Reynolds equation. Duwensee et al. [15] have used the DSMC method to study the pressure generation in a nano slider covering one groove and land region for DTR type disk.

In the present article, we present a direct numerical simulation that investigates the head/disk interface for patterned media by considering the entire slider ABS with ability to resolve the pressure gradients caused by nanometer high periodic surface patterns. A finite-elementbased solution of the Reynolds equation is used to obtain the steady state flying characteristics of the patterned head/ disk interface. The steady state flying behavior of typical proximity recording sliders with surface patterns and the effect of pattern pitch, diameter and height is investigated for five sub-ambient pressure slider bearings. In areas of high pressure and low spacing, a very fine mesh is selected to investigate the effect of the ultra small features and determine the influence of pattern on the air bearing pressure. In areas of higher spacing, a coarser finite element mesh was chosen, since the influence of surface features is decreasing with increasing spacing. The numerical approach is similar to that used by Duwensee et al. [10] in the study of the head/disk interface for discrete track media. Finally, the flying height change due to bit pattern is compared with the results for DTR [10].

\section{Simulation Model}

Figure 1 shows the transfer of the bit pattern from the disk surface to the slider ABS. As can be seen, the pattern is present on the center trailing pad of the slider and is modeled as cylindrical protrusions of diameter $d$, height $h$, and pitch $p$. The protrusions are uniformly distributed representing the pattern from the disk in the radial and circumferential directions.

Figure 2 shows the definition of the patterned slider parameters. In Fig. 2, ' $p$ ' denotes the pattern pitch, ' $d$ ' denotes the pattern diameter, and ' $h$ ' denotes the pattern height. The same pitch $p$ is used both in the length and the width directions of the slider. The nearest distance between two pattern features in both the length and the width directions of the slider is ' $(p-d)$ '. 


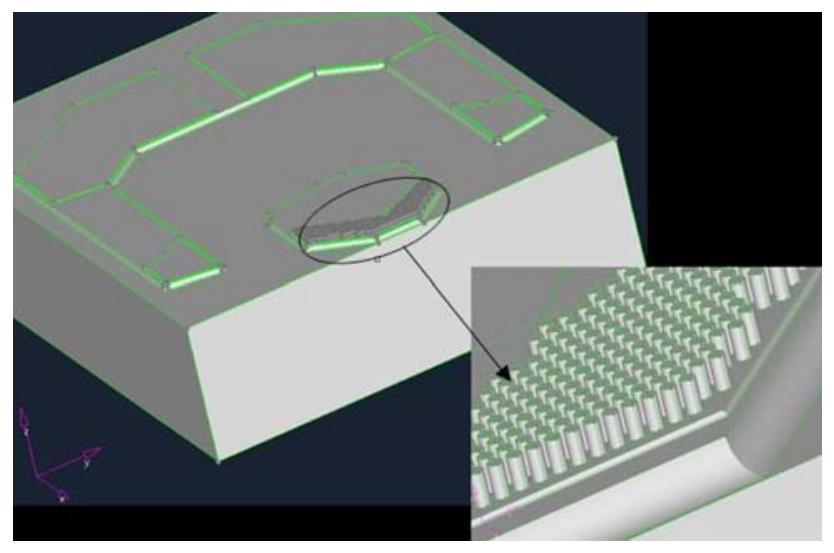

Fig. 1 Schematic of pattern transfer from disk to trailing pad of slider air bearing
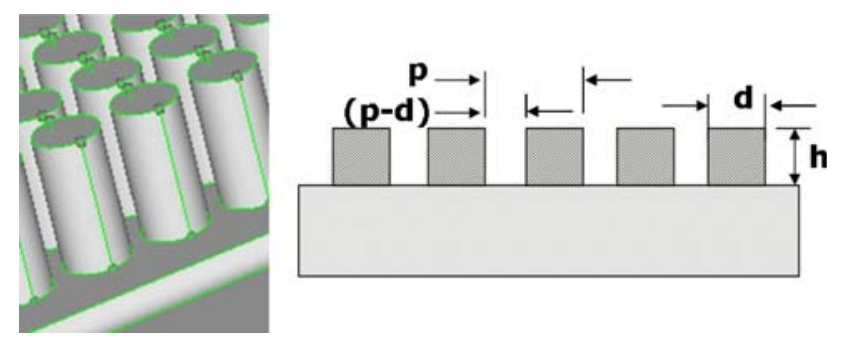

Fig. 2 Definition of pattern pitch $(p)$, pattern diameter $(d)$, and pattern height $(h)$

The air bearing pressure distribution and equilibrium position are obtained by a finite element solution of the steady state Reynolds equation $[3,16]$ given by:

$\frac{\partial}{\partial x}\left(\bar{Q} p h^{3} \frac{\partial p}{\partial x}\right)+\frac{\partial}{\partial y}\left(\bar{Q} p h^{3} \frac{\partial p}{\partial y}\right)=6 \mu\left(U \frac{\partial p h}{\partial x}+V \frac{\partial p h}{\partial y}\right)$

where $\bar{Q}$ denotes the Boltzmann slip flow correction for rarefied gas flow [17, 18], $p$ is the pressure, $h$ is the spacing between the slider and the disk, $\mu$ is the dynamic viscosity of air, $U$ and $V$ are the velocity components in the $x$ and $y$ directions, respectively.

Four "femto" form factor slider designs with different steady state flying characteristics were investigated as a function of pattern design parameters (Fig. 3). These slider designs were previously investigated by Duwensee et al. [10] for discrete track media. The four femto sliders shown in Fig. 3 have steady state flying heights of 30, 14, 15, and $19 \mathrm{~nm}$, respectively, on a conventional smooth disk. The four femto sliders are design modifications of the femto slider shown in Fig. 3a. The steady state pitch angles of the four femto designs on a smooth disk surface are 250, 170, 166 , and $154 \mu \mathrm{rad}$, respectively.

In the initial calculation, a fairly large pattern diameter of $3 \mu \mathrm{m}$ was used for the slider shown in Fig. 1 to obtain the pressure generation around the pattern features. Large diameter pattern features were chosen for visualizing the effect of pattern on air bearing pressure.

For the four femto designs shown in Fig. 3, pattern heights between 0 and $40 \mathrm{~nm}(0<d<40 \mathrm{~nm})$ were investigated. A pattern diameter between 200 and $800 \mathrm{~nm}$ was used with a constant pattern pitch of $1000 \mathrm{~nm}$. In addition, the influence of skew angle (ranging from $0^{\circ}$ to $20^{\circ}$ ), the effect of slider pitch angle, and the effect of pattern diameter were investigated. Due to the small pattern features on the trailing edge center pad, a very fine mesh discretization was required. A uniform mesh density over the complete ABS would result in numerical models with several tens of millions of nodes. To reduce the model size, a non-uniform mesh was used for the simulation. Very small elements were used in the area where the pattern features are present and increasingly larger sized elements elsewhere. In particular, about 30-50 elements were created for each individual pattern. The number of pattern features on the trailing edge center pad of the femto slider designs was on the order of 5000-8000. For example, slider design 3 (Fig. 3c) had a center trailing pad area of about $140 \times 40 \mu \mathrm{m}$ resulting in 5600 pattern features. The total number of nodes and elements for this slider model was on the order of $0.7 \times 10^{6}$ and $1.4 \times 10^{6}$, respectively.

\section{Numerical Simulation Results}

Figure 4 shows the steady state pressure distribution for the femto air bearing design shown in Fig. 1. In Fig. 4, a large pattern diameter of about $3 \mu \mathrm{m}$ was chosen to elucidate the pressure generated around individual pattern features. Figure $4 \mathrm{~b}$ shows the pressure for the pattern features on the center trailing pad. We observe that large pressure changes occur locally at each pattern feature. Figure $4 \mathrm{c}$ shows the side view of the pressure along the slider centerline. We observe that the pressure increases locally around the converging portions of each pattern feature. In the diverging spacing region of the pattern feature, the pressure decreases. A single pattern feature is similar to a Rayleigh step bearing with converging and diverging sections. We also observe from Fig. $4 \mathrm{c}$ that the maximum pressure occurs on the pattern features closest to the trailing edge of the slider due to the pitch angle of the slider.

Figure 5 shows the comparison of the pressure distribution for a non-patterned slider and a patterned slider. The diameter and height of the pattern used in Fig. $5 \mathrm{~b}$ are $3 \mu \mathrm{m}$ and $20 \mathrm{~nm}$, respectively. From Fig. 5b we observe that the pressure distribution on the center trailing pad, where the pattern is present, is quite different from Fig. 5a. The maximum pressure generated for a patterned slider is larger than the maximum pressure for a non-patterned slider. 
Fig. 3 Femto form factor slider air bearing designs $1,2,3$, and 4 (labeled a-d, respectively) [10]

Fig. 4 Steady state pressure distribution for: a patterned air bearing slider, $\mathbf{b}$ zoom in plot for pressure on the center trailing pad with pattern, c side view along the slider centerline
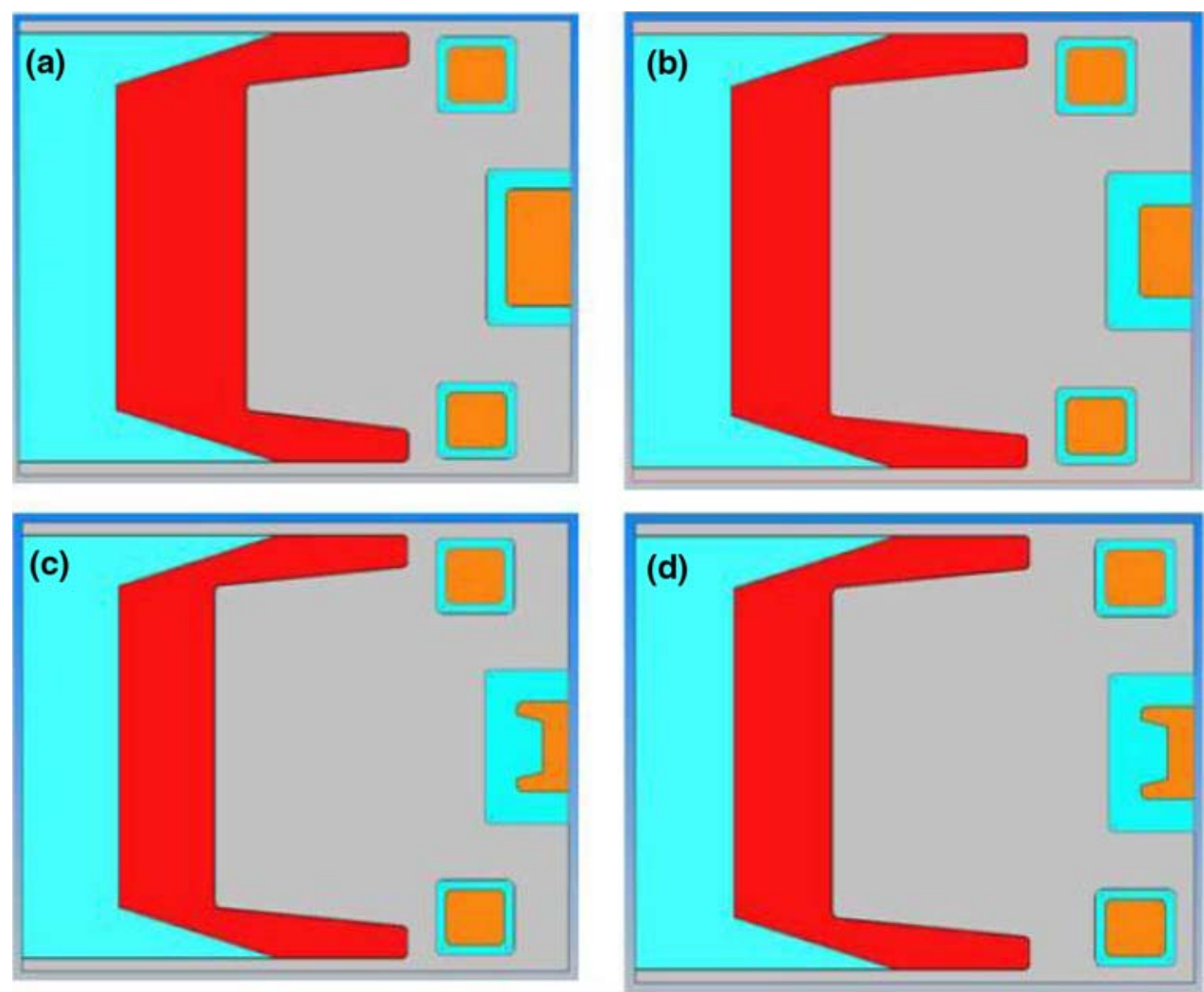

\section{Numerical Simulation Results}

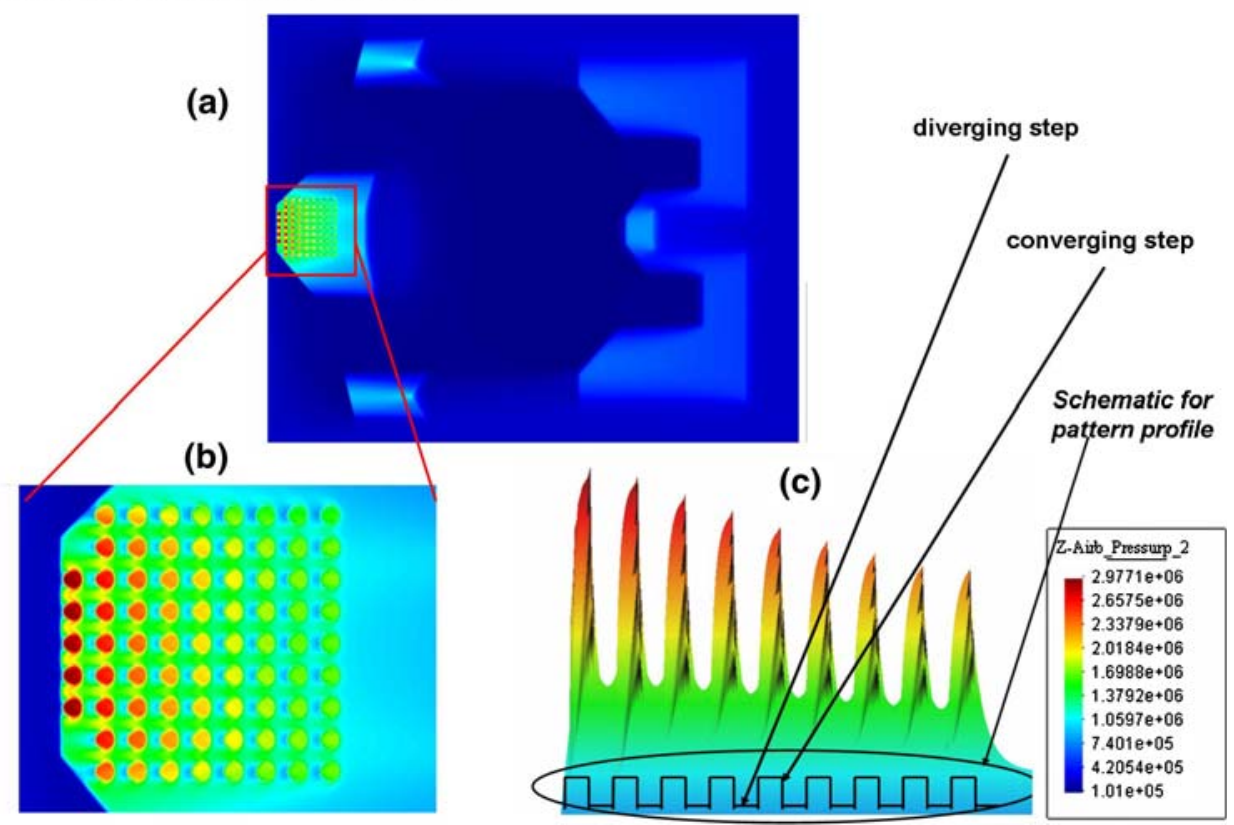

In Fig. 6, we have plotted the pressure profile along the width of the slider. We observe that high pressure peaks occur at each pattern feature, superimposed on a smooth background pressure. These pressure peaks are present over each pattern feature in both the length and width directions of the slider. The top surface of each pattern feature is the area in closest proximity to the disk surface. These areas represent the minimum spacing. The recessed regions of the patterned features and the other regions of the ABS are farther away from the disk surface. Hence, an 

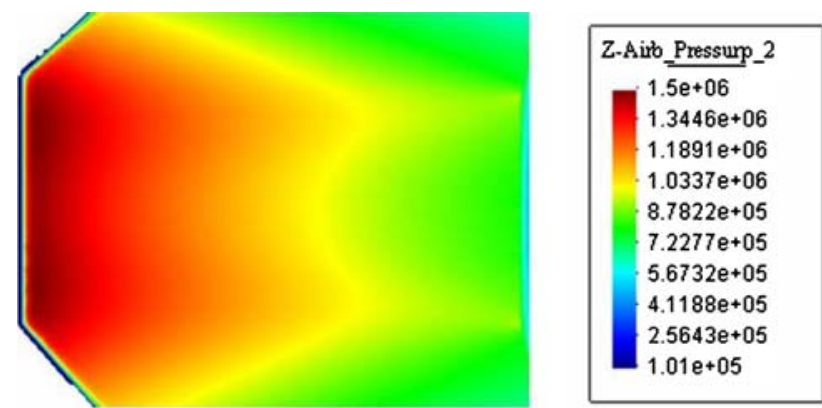

(a)

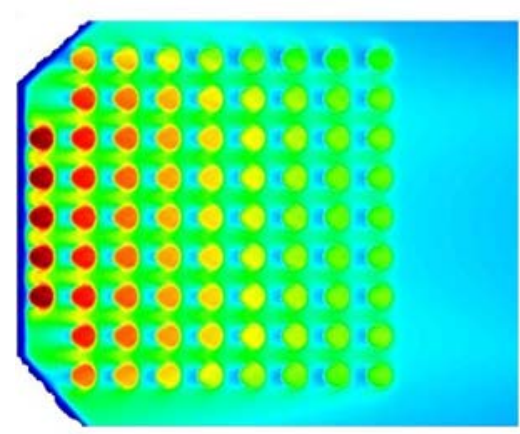

\begin{tabular}{|c|}
\hline Z-Airb_Pressump_2 \\
$2.9771 e+06$ \\
$2.6575 e+06$ \\
$2.3379 e+06$ \\
$2.0184 e+06$ \\
$1.6988 e+06$ \\
$1.3792 e+06$ \\
$1.0597 e+06$ \\
$7.401 e+05$ \\
$4.2054 e+05$ \\
$1.01 e+05$
\end{tabular}

(b)

Fig. 5 Steady state pressure distribution for a a non-patterned ABS and $\mathbf{b}$ a patterned ABS

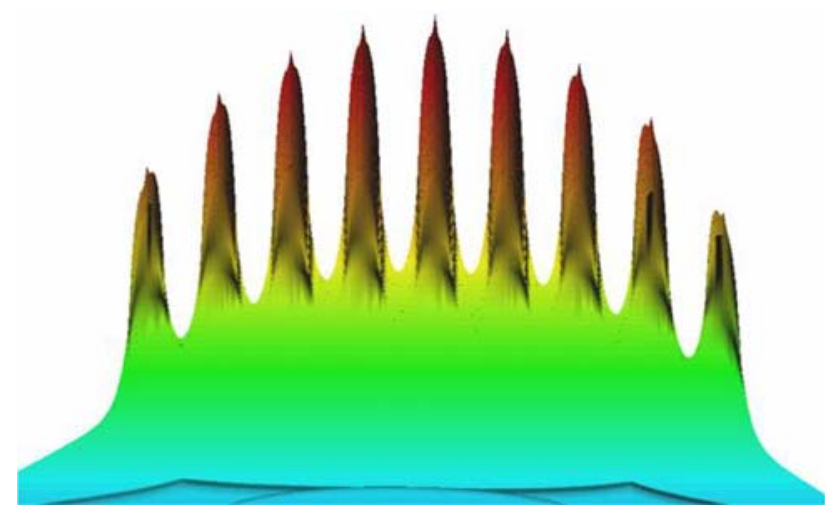

Fig. 6 Pressure peaks due to pattern on ABS center trailing pad (looking from the trailing edge toward the leading edge)

increase of local air bearing pressure in areas close to the disk surface is to be expected. The high pressure spikes are likely to cause lubricant migration or lubricant depletion.

To investigate the effect of pattern height, pattern diameter, slider skew, and pitch angles on flying height, a parametric study was performed.

Figure 7 shows the trailing edge center spacing as a function of the pattern height for the femto slider designs shown in Fig. 3. For this calculation, the ratio of diameter to pitch of the pattern features was kept constant at 0.5. From Fig. 7, we observe that the trailing edge center spacing decreases with increasing pattern height. We also observe

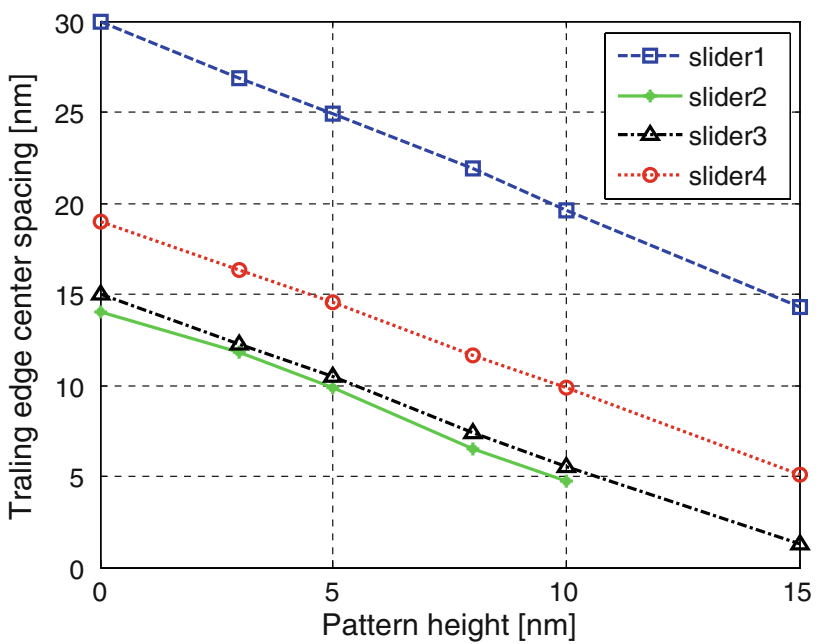

Fig. 7 Trailing edge center spacing as a function of pattern height for slider designs $1,2,3$, and 4 keeping $d / p$ constant at 0.5

that the slope of the flying height versus pattern height curve is similar for all four slider air bearing designs.

The flying height loss of the four femto sliders as a function of pattern height $h$ is plotted in Fig. 8 for a ratio of $d / p=0.5$. We observe that the flying height decreases linearly as a function of the pattern height. That trend is similar for all four slider designs.

The steady state flying height of a patterned slider disk interface with a constant ratio of $d / p=0.5$ can be estimated by subtracting $\Delta \mathrm{FH}$ from the flying height on a conventional smooth head/disk interface. The dotted line in Fig. 8 was obtained using the following equation:

$\Delta \mathrm{FH}=2 h\left(\frac{d}{p}\right)$

Buscaglia et al. have done extensive theoretical analysis on the effect of surface textures for load carrying capacity

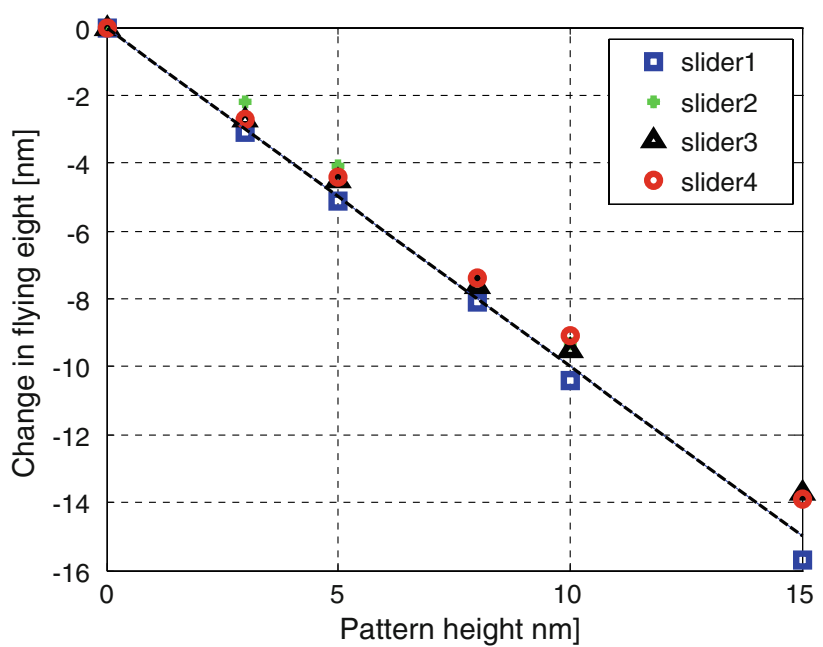

Fig. 8 Change in flying height as a function of pattern height for femto slider designs $(d / p=0.5)$ 


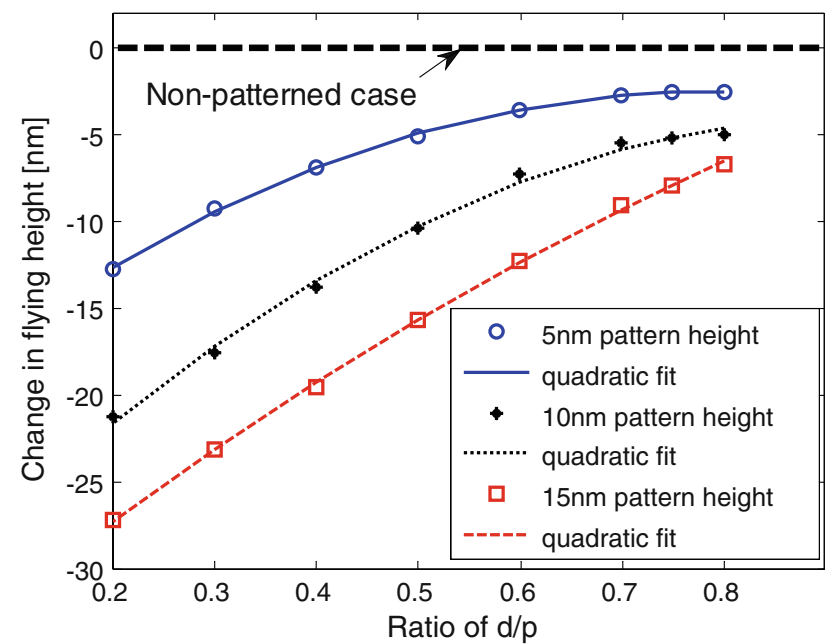

Fig. 9 Change in flying height as a function of the ratio $d / p$ for femto slider design 1

(which is the integration of the pressure) in thrust bearings [19] and then extended the study in [20] to account for compressibility. In both these studies it was shown that the load carrying capacity is a function of the mean depth of surface textures only. Equation 2 above is analogous to Buscaglia et al. finding because " $h$ " is not only the pattern height, it is also the depth of the recessed areas around the pattern. For a given ratio of $d / p$, change in flying height (which is a function of pressure) is directly proportional to " $h$ ". However, when the $d / p$ ratio is varied as in Fig. 9, non-linear effects are observed. In fact the change in flying height fits well with a quadratic function and is later shown to be an area effect. We observe the higher order effects due to the surface patterns because of the use of direct simulation compared to homogenized solution in [20].

Figure 9 shows the change in flying height as a function of the pattern diameter. The change in flying height is plotted as a function of the ratio $d / p$. The dashed horizontal line in Fig. 9 corresponds to the non-patterned case. In Fig. 9, the pattern diameter was varied between 200 and $800 \mathrm{~nm}$ keeping the pattern pitch constant at $1000 \mathrm{~nm}$. From Fig. 9 we observe that the change in flying height is non-linear as a function of the pattern diameter. The solid, dotted, and dashed lines in Fig. 9 represent a quadratic fit for a pattern height of 5,10, and $15 \mathrm{~nm}$, respectively.

Figure 10 shows the trailing edge center spacing of femto slider design 1 as a function of the pattern height for skew angles of $0^{\circ}, 5^{\circ}, 10^{\circ}$, and $20^{\circ}$, respectively. The ratio of the pattern diameter to the pattern pitch was chosen to be one half $(d / p=0.5)$. A linear decrease in the trailing edge center spacing is observed with increasing pattern height, indicating that Eq. 2 applies also for non-zero skew cases.

The effect of the slider pitch angle on pattern height is shown in Fig. 11. From the simulation results, we observe

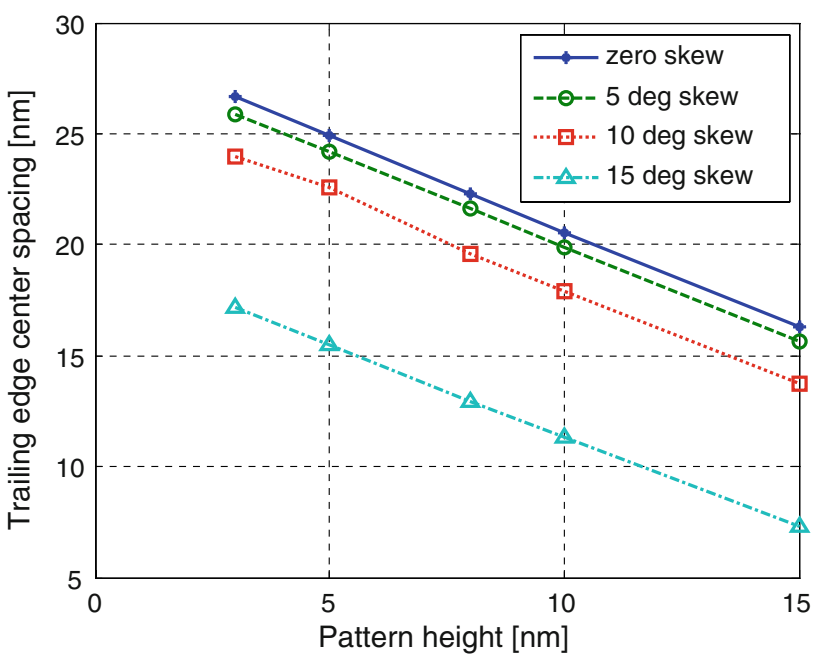

Fig. 10 Trailing edge center spacing as a function of slider skew angle for femto slider design 1

(a)

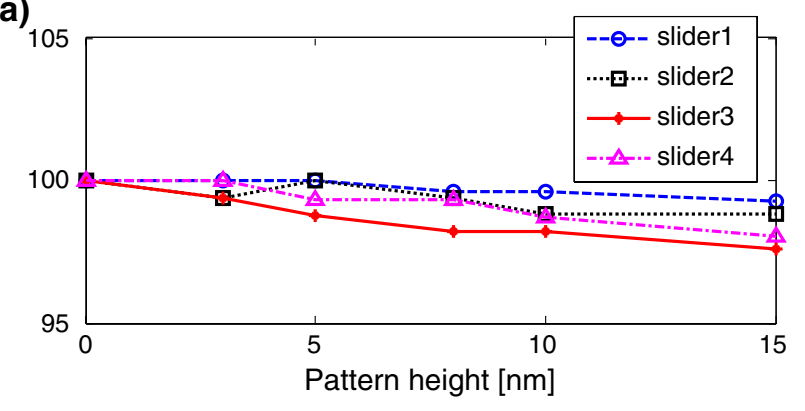

(b)

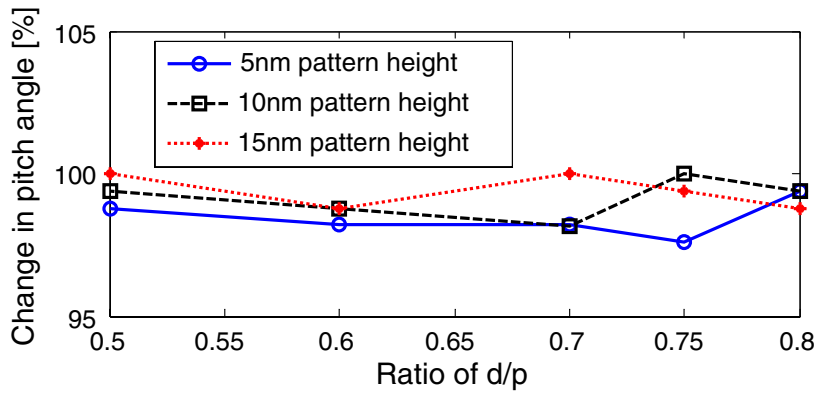

(c)

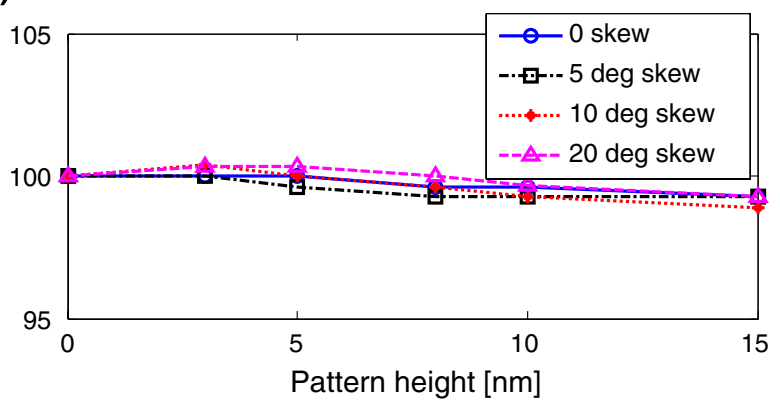

Fig. 11 Pitch angle change versus a pattern height for different femto slider designs, b ratio $d / p$ (slider design 3 ), and $\mathbf{c}$ pattern height for different skew angles (slider design 3 ) 


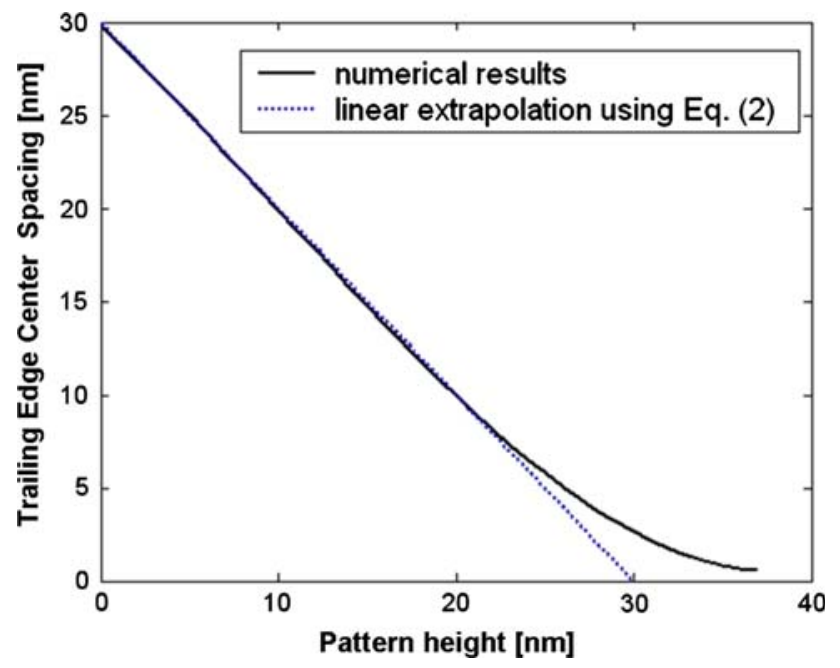

Fig. 12 Trailing edge spacing versus pattern height (slider 1)

that the change in the slider pitch angle is almost independent of slider air bearing design, pattern height, the ratio $d / p$, and the slider skew angle. From Fig. 11, we conclude that the presence of pattern with diameter on the order of several nanometers does not affect the pitch angle of the slider body.

To determine the general relationship between flying height and pattern height, the trailing edge center spacing was computed by increasing the pattern height for slider design 1 until the flying height reaches zero, i.e., until contact between slider and disk occurs (Fig. 12). In the calculation for Fig. 12, the pattern diameter and pitch were 500 and $1000 \mathrm{~nm}$, respectively. From the linear extrapolation of the flying height using Eq. 2 for slider design 1, we observe that contact occurs for a pattern height of $30 \mathrm{~nm}$. However, from the numerical simulation using the finite element solution of the Reynolds equation, we observe that the numerical results for flying height deviate from the predicted values for pattern heights larger than $20 \mathrm{~nm}$ for slider design 1. Thus, it is apparent that the linear approximation for flying height loss is valid for only small pattern heights. Beyond a critical value of pattern height, the change in flying height is non-linear and a full air bearing simulation is necessary to compute the change in flying height correctly.

\section{Discussion and Summary}

From our simulation results we observe that the flying height decreases as a function of pattern height and the ratio of pattern diameter to pattern pitch. Our calculations show that the reduction in flying height is a linear function of the pattern height for small values of pattern height.
Beyond a certain value for the pattern height, the change in flying height becomes non-linear. For the patterned slider simulations shown in this paper, Eq. 2 can be used to predict the change in flying height for small pattern heights and for a ratio of pattern diameter to pattern pitch equal to one half. Duwensee et al. [10] obtained an empirical equation that predicts the change in flying height for DTR media as follows [10]:

$\Delta \mathrm{FH}=$ groove depth $\times($ groove width/groove pitch $)$

Comparing this equation to our simulation results for a bit-patterned slider disk interface, we observe that the groove depth of discrete track disks is analogous to the pattern height of a bit-patterned disk, and that the groove width is analogous to the area recessed around a pattern feature. In addition, the groove pitch is similar to the pattern pitch. For a DTR interface, the flying height loss is linearly proportional to the groove depth and the ratio of groove width to groove pitch for any value of groove depth and groove width for a constant groove pitch [10]. This is due to the fact that the length of the groove and the land regions of the discrete track are the same and that the groove pattern is unidirectional.

A non-linear change in flying height was observed for a bit-patterned slider disk interface when the pattern diameter was varied. The change in flying height was found to be a quadratic function of the pattern diameter. This result is to be expected since a change in the pattern diameter not only changes the pattern profile along the width of the slider, but also along the length of the slider. For the DTR interface, a change in width changes the pattern profile only along the width of the slider. For a range of different pattern diameters and pitch ratios, a functional relationship would have to be written as $\Delta \mathrm{FH}=f(h) \times f(d / p)$. The value of $f(d / p)$ is different for various ratios of pattern diameter to pattern pitch.

For a DTR interface, an area ratio representing the ratio of recessed area due to groove width to the area due to groove pitch can be written as $w / p$. For the patterned slider disk interface, a similar area ratio can be obtained as:

$\frac{A_{\text {recessed }}}{A}=1-\frac{\pi d^{2}}{4 p^{2}}$

To compare the two types of patterned media, we plotted in Fig. 13 the change in flying height as a function of the area ratio as defined in Eq. 3. In Fig. 13, the pattern height was $10 \mathrm{~nm}$ and the groove depth was $10 \mathrm{~nm}$ for DTR media. The results are shown for slider design 1 . The data for the DTR media was obtained using the empirical equation obtained by Duwensee et al. [10]. From Fig. 13, we observe that the flying height loss increases as the area ratio increases for both DTR and bit-patterned slider disk interface. However, the change in flying height for the bit- 


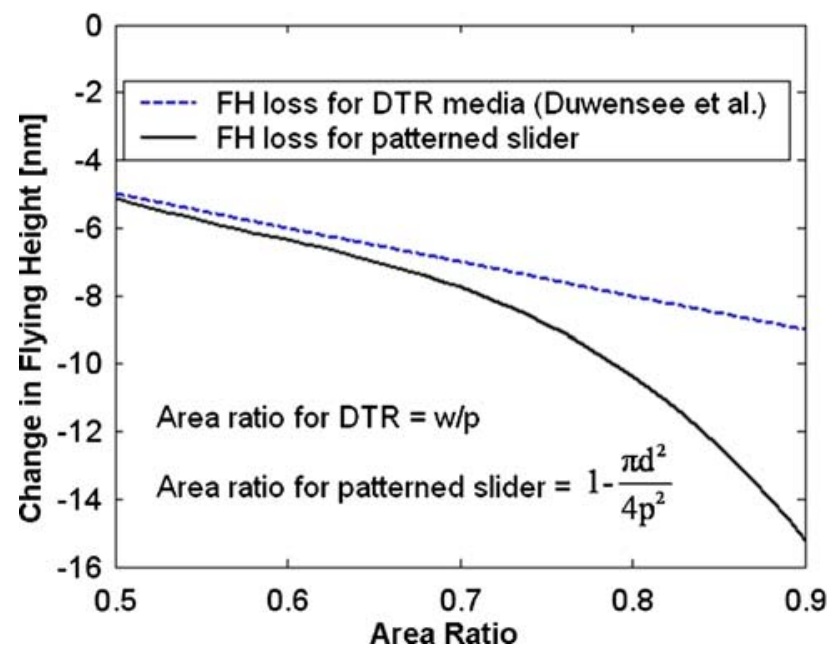

Fig. 13 Comparison of change in flying height for discrete track recording and bit-patterned slider as a function of the area ratio (slider $1,10 \mathrm{~nm}$ groove depth or pattern height)

patterned interface is higher as the area ratio increases compared to the DTR interface. This latter result is to be expected since side flow is more prevalent in the discrete bit-patterned case than in the discrete track case. In Fig. 13, an area ratio less than 0.5 would represent pattern diameter values that are close to the pattern pitch values. Area ratios greater than 0.9 represent very small pattern diameters that are on the order of tens of nanometers.

For smaller pattern diameters, the change in flying height increases by larger amplitude for the bit-patterned interface compared to the DTR interface, as the recessed area ratio increases.

\section{Conclusions}

1. High pressure peaks occur locally over each pattern feature. These high pressure areas are likely to cause lubricant loss over the bit areas.

2. From the parametric analysis of several femto slider designs, it was found that the slider flying height decreases linearly with increasing pattern height. The flying height decreases quadratically with the ratio of $d / p$.

3. The flying height loss of a discrete bit-patterned media is a linear function for small values of pattern height keeping pattern diameter and pattern pitch constant.

4. The slider pitch angle was found to be independent of pattern height, slider design, and skew angle.

5. The flying height loss is larger for a bit-patterned slider disk interface compared to a discrete track interface for the same recessed area of pattern.
Open Access This article is distributed under the terms of the Creative Commons Attribution Noncommercial License which permits any noncommercial use, distribution, and reproduction in any medium, provided the original author(s) and source are credited.

\section{References}

1. Albrecht, M., Rettner, C.T., Thomson, T., McClelland, G.M., Hart, M.W., Anders, S., Best, M.E., Terris, B.D.: Magnetic recording on patterned media, Joint NAPMRC 2003, 6-8 Jan 2003, p. 36

2. Wachenschwanz, D., Jiang, W., Roddick, E., et al.: Design of a manufacturable discrete track recording medium. IEEE Trans. Mag. 41(2), 670-675 (2005)

3. Duwensee, M., Suzuki, S., Lin, J., Wachenschwanz, D., Talke, F.: Air bearing simulation of discrete track recording media. IEEE Trans. Mag. 42(10), 2489-2491 (2006)

4. Gui, J., Tang, H., Wang, L.-P., Rauch, G.C., Boutaghou, Z., Hanchi, J., Pitchford, T., Segar, P.: Slip sliding away: a novel head disk interface and its tribology. J. Appl. Phys. 87, 5383$5388(2000)$

5. Fua, T.-C., Suzuki, S.: Low stiction/low glide height head disk interface for high-performance disk drive. J. Appl. Phys. 85, 5600-5605 (1999)

6. Li, W.-L., Lee, S.-C., Chen, C.-W., Tsai, F.-R., Chen, M.-D., Chien, W.-T.: The flying height analysis of patterned sliders in magnetic hard disk drives. Microsyst. Technol. 11(1), 23-31 (2005)

7. Tagawa, N., Bogy, D.: Air film dynamics for micro-textured flying head slider bearings in magnetic hard disk drives. ASME J. Tribol. 124, 568-574 (2002)

8. Tagawa, N., Hayashi, T., Mori, A.: Effects of moving threedimensional nano-textured disk surfaces on thin film gas lubrication characteristics for flying head slider bearings in magnetic storage. ASME J. Tribol. 123, 151-158 (2001)

9. Tagawa, N., Mori, A.: Thin film gas lubrication characteristics of flying head slider bearings over patterned media in hard disk drives. Microsyst. Technol. 9, 362-368 (2003)

10. Duwensee, M., Suzuki, S., Lin, J., Wachenschwanz, D., Talke, F.: Simulation of the head disk interface for discrete track media. Microsyst. Technol. 13(8-10), 1023-1030 (2006)

11. Buscaglia, G., Jai, M.: Homogenization of the generalized Reynolds equation for ultrathin gas films and its resolution by FEM. ASME J. Tribol. 126, 547-552 (2004)

12. Alexander, F., Garcia, A., Alder, B.: Direct simulation Monte Carlo for thin-film bearings. Phys. Fluids 6(12), 3854-3860 (1994)

13. Huang, W., Bogy, D., Garcia, A.: Three-dimensional direct simulation Monte Carlo method for slider air bearings. Phys. Fluids 9(6), 1764-1769 (1997)

14. Huang, W., Bogy, D.: An investigation of a slider air bearing with an asperity contact by a three dimensional direct simulation Monte Carlo method. IEEE Trans. Mag. 34(4), 1810-1812 (1998)

15. Duwensee, M., Suzuki, S., Lin, J., Wachenschwanz, D., Talke, F. Direct simulation Monte Carlo method for the simulation of rarefied gas flow in discrete track recording head/disk interfaces. ASME J. Tribol. 131(1), 12001-12007 (2009)

16. Wahl, M., Lee, P., Talke, F.: An efficient finite element-based air bearing simulator for pivoted slider bearings using bi-conjugate gradient algorithms. STLE Tribol. Trans. 39(1), 130-138 (1996)

17. Fukui, S., Kaneko, R.: Analysis of ultra-thin gas film lubrication based on linearized Boltzmann equation: first report-derivation of a generalized lubrication equation including thermal creep flow. ASME J. Tribol. 110, 253-262 (1988) 
18. Fukui, S., Kaneko, R.: A database for interpolation of Poiseuille flow rates of High Knudsen number lubrication problems. ASME J. Tribol. 112, 78 (1990)

19. Buscaglia, G., Ciuperca, I., Jai, M.: The effect of periodic textures on the static characteristics of thrust bearings. ASME J. Tribol. 127, 899-902 (2005)
20. Buscaglia, G., Ciuperca, I., Jai, M.: On the optimization of surface textures for lubricated contacts. J. Math. Anal. Appl. 335, 1309-1327 (2007) 